\title{
Selective laser trabeculoplasty for elevated intraocular pressure following subtenon injection of triamcinolone acetonide
}

This article was published in the following Dove Press journal:

Clinical Ophthalmology

30 March 2010

Number of times this article has been viewed

\author{
Kenya Yuki' \\ Makoto Inoue ${ }^{1,2}$ \\ Daisuke Shiba' \\ Ryosuke Kawamura' \\ Susumu Ishida' \\ Yuichiro Ohtake' \\ 'Department of Ophthalmology, Keio \\ University School of Medicine, \\ ${ }^{2}$ Kyorin Eye Center, Kyorin University \\ School of Medicine, Mitaka, Tokyo, \\ Japan
}

Purpose: To report on the efficacy of selective laser trabeculoplasty (SLT) for elevated intraocular pressure (IOP) following subtenon injection of triamcinolone acetonide.

Method: SLT was performed on four of 148 eyes in which IOP was elevated after a subtenon injection of triamcinolone acetonide and could not be maintained within normal limits by conventional medications. Postoperative IOP and relative reduction of IOP were evaluated.

Results: IOP was reduced in three eyes to within the normal range without any medications six months after SLT alone, but trabeculotomy was performed on one eye. Percentage reduction in IOP after SLT was $21.6 \%$ at one month, $45.0 \%$ at three months, and $52.7 \%$ at nine months.

Conclusion: SLT may be effective in reducing elevated IOP following subtenon injection of triamcinolone acetonide and should be considered before glaucoma surgery.

Keywords: selective laser trabeculoplasty, steroid glaucoma, subtenon injection, triamcinolone acetonide

\section{Introduction}

One complication of intravitreal or subtenon injection of triamcinolone acetonide (SITA) is an elevation of intraocular pressure (IOP). ${ }^{1}$ Argon laser trabeculoplasty and selective laser trabeculoplasty (SLT) have been used to treat elevated IOP following intravitreal injection of triamcinolone acetonide (IVTA). ${ }^{2,3}$ However, the elevation of the IOP after SITA is different from that following IVTA because a higher dose is injected which may have a long-lasting effect. ${ }^{4}$ The effectiveness of SLT following SITA has not been examined. Thus, we have investigated whether SLT is effective in reducing elevated IOP after SITA.

\section{Methods}

SITA of 10 or $20 \mathrm{mg}$ was performed on 148 eyes between 2004 and 2006 at the Keio University Hospital. Written informed consent was obtained from all patients before SITA. Institutional approval was obtained for this retrospective clinical review. All patients were followed for at least nine months.

IOP was measured before and after SITA by Goldmann applanation tonometry. SLT was performed when IOP had increased to $>26 \mathrm{mmHg}$ with intensive medications, including topical ocular medications and oral acetazolamide. Postoperative IOP and relative reduction of IOP were evaluated.

A Nd:YAG half-wave Q switch laser (SELECTA duet, Japan Lumenis, Tokyo) was used for the SLT at a wavelength at $532 \mathrm{~nm}$, spot size $400 \mu \mathrm{m}$, and exposure time of 3 nsec. Forty spots were applied to the inferior $180^{\circ}$ sector with an energy of
Correspondence: Makoto Inoue Kyorin Eye Center, Kyorin University School of Medicine, 6-20-2 Shinkawa, Mitaka, Tokyo I8I-86II, Japan Tel +8 I 4224755 I I Ext 2606 Fax +8I 422469309

Email inoshin007@mac.com 
0.8 to $1.0 \mathrm{~mJ}$, and small gas bubbles were observed after each shot. The preoperative topical and systemic medications were continued postoperatively. Topical hydrochloric apraclonidine was applied 30 minutes before and immediately after the SLT procedure. Anti-inflammatory medications, such as steroid eye drops, were not used.

\section{Results}

SITA of 10 or $20 \mathrm{mg}$ was performed for retinal vein occlusion, choroidal neovascularization, or diabetic maculopathy before anti-vascular endothelial growth factor therapy was introduced. IOP increased to $>21 \mathrm{mmHg}$ in $44(30 \%)$ of 148 eyes after SITA, and anti-glaucoma medications were used. SLT was performed in four eyes of four patients (one man and three women, mean age $37.5 \pm 7.3$ years) from two to three months after SITA when the IOP had not decreased after the use of anti-glaucoma medications. In the other 144 eyes, the IOP gradually decreased to baseline IOP in 10 months, with a reduction in the number of anti-glaucoma medications. The IOP before SITA in the four eyes in which SLT was performed ranged between 14 and $19 \mathrm{mmHg}$. The angle was classified as Shaffer 3 by gonioscopy. There was no evidence of angle neovascularization before SITA and SLT treatment (Table 1). The presence of glaucomatous disc cupping $^{5,6}$ which was defined as a vertical cup-to-disc ratio $>0.7$ or a difference in the vertical cup-to-disc ratio between the two eyes $>0.2$ was not detected before SLT treatment. In addition, a decrease in sensitivity in the visual fields on Humphrey perimetric tests associated with ocular hypertension was also not present before the SLT treatment.

In three eyes, the mean \pm standard deviation of the IOP before the SLT was $28.7 \pm 2.1 \mathrm{mmHg}$, and the postoperative mean IOP was $23.3 \mathrm{mmHg}$ at one month, $28.0 \mathrm{mmHg}$ at two months, $15.0 \mathrm{mmHg}$ at three months, $15.3 \mathrm{mmHg}$ at six months, and $13.3 \mathrm{mmHg}$ at nine months. The percentage reduction in IOP was $21.6 \% \pm 16.9 \%, 6.0 \% \pm 7.2 \%$, $45.0 \% \pm 26.9 \%, 48.0 \% \pm 14.1 \%$, and $52.7 \% \pm 3.0 \%$ at the corresponding times. IOP in case 4 increased to $40 \mathrm{mmHg}$ at four weeks after SLT and trabeculotomy (incision into
Schlemm's canal ab externo) was performed. ${ }^{7}$ In all cases, the ocular anti-hypertensive medications were discontinued after six months.

\section{Discussion}

SLT has been performed for open angle glaucoma, ocular hypertension, and steroid-induced glaucoma ${ }^{3,8}$ because it is less damaging to the trabecular meshwork. ${ }^{9}$ SLT was reported to reduce the mean IOP by $30 \%(7.7 \pm 3.5 \mathrm{mmHg})$ for eyes with primary open-angle glaucoma. ${ }^{10}$ In our three eyes with a good response to SLT, IOP was reduced by $52.7 \% \pm 3.0 \%$ at nine months, which was greater than that for eyes with primary open-angle glaucoma. SLT may be more effective for steroid-induced glaucoma after IVTA. ${ }^{3}$

It is possible that the disappearance of the drug from the subtenon space may have lowered the IOP. However, the typical increase in IOP response after IVTA has been reported to occur within one week in early cases but, in general, the increase in IOP peaks after a few months with a gradual decline to baseline between six to nine months after the injection. ${ }^{1,11-13}$ There are reports concluding that young age is a risk factor for elevated IOP after SITA and IVTA. ${ }^{1,4}$ Our findings suggested that SLT might lower the IOP from one month after SLT more effectively than the disappearance of the drug. In addition, SLT may be more effective for steroid-induced glaucoma as described for IVTA. ${ }^{3}$ However, we acknowledge that because of the lack of a treatment control group and the limited number of patients in the treatment group there exists the potential for misleading conclusions. Further investigations on a larger number of eyes are necessary to determine the efficacy of SLT by comparing the decrease with the natural decrease of IOP back to baseline.

\section{Acknowledgments}

The authors received no grant support in reporting their clinical observations. The corresponding author (MI) has full access to all the data in the study and takes responsibility for the integrity of the data and the accuracy of the data

Table I Preoperative condition of patients

\begin{tabular}{lllllll}
\hline Case & Age & Gender & Baseline IOP $\mathbf{( m m H g )}$ & TA injection $\mathbf{( m g})$ & Preop IOP $(\mathbf{m m H g})$ & Preop medication \\
\hline I & 47 & W & 19 & 20 & 27 & PG, beta, CAI \\
2 & 39 & M & 17 & 20 & 28 & PG, beta, CAl, oral CAI \\
3 & 34 & W & 17 & 10 & 30 & PG, beta, CAI \\
4 & 30 & W & 14 & 20 & 35 & PG, beta, CAI, oral CAI \\
\hline
\end{tabular}

Abbreviations: F, woman; M, man; IOP, intraocular pressure; PG, latanoprost; beta, $2 \%$ hydrochloric carteolol; CAI, topical dorzolamide; oral CAI, systemic acetazolamide; TA, triamcinolone acetonide. 


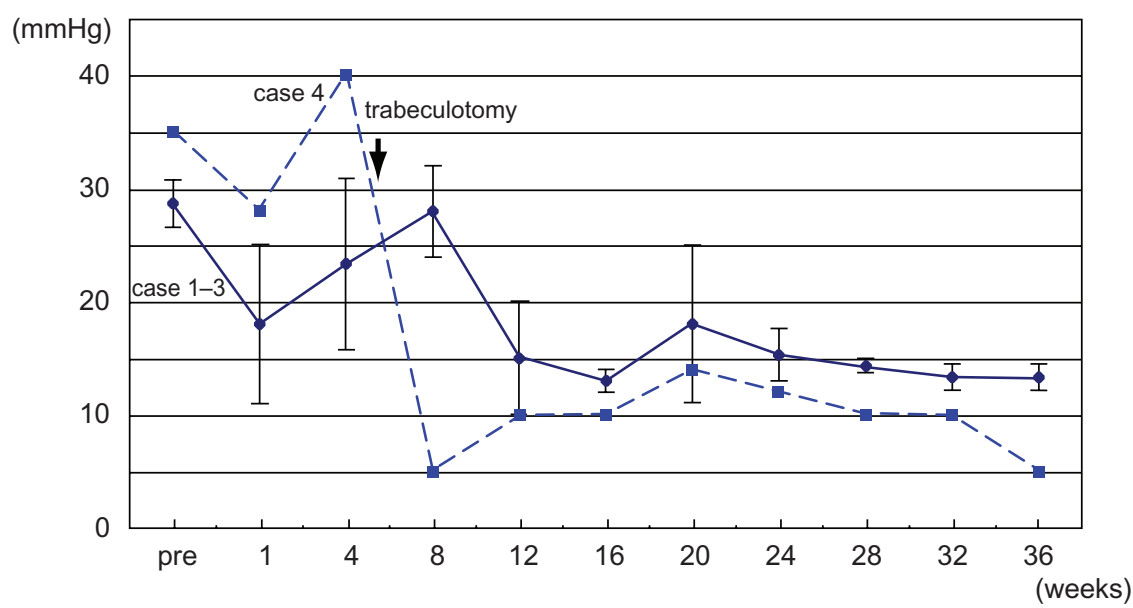

Figure I Mean intraocular pressure (IOP) before and after SLT. The IOP decreases gradually in three eyes and one eye had a trabeculotomy (case 4). Abbreviations: IOP, intraocular pressure; SLT, selective laser trabeculoplasty.

analysis. KY, DS, RK, and SI analyzed and interpreted the patient data. MI, YK, and YO were major contributors in writing the manuscript. All authors read and approved the final manuscript.

\section{References}

1. Jonas JB, Degenring RF, Kreissig I, Akkoyun I, Kamppeter BA. Intraocular pressure elevation after intravitreal triamcinolone acetonide injection. Ophthalmology. 2005;112:593-598.

2. Viola F, Morescalchi F, Staurenghi G. Argon laser trabeculoplasty for intractable glaucoma following intravitreal triamcinolone. Arch Ophthalmol. 2006;124:133-134

3. Pizzimenti JJ, Nickerson MM, Pizzmenti CE, Kasten-Aker AG. Selective laser trabeculoplasty for intraocular pressure elevation after intravitreal triamcinolone acetonide injection. Optom Vis Sci. 2006;83:421-425.

4. Yamamoto Y, Komatsu T, Koura Y, Nishino K, Fukushima A, Ueno H. Intraocular pressure elevation after intravitreal or posterior sub-Tenon triamcinolone acetonide injection. Can J Ophthalmol. 2008;43: 42-47.

5. Foster PJ, Buhrmann R, Quigley HA, Johnson GJ. The definition and classification of glaucoma in prevalence surveys. $\mathrm{Br} J$ Ophthalmol. 2002;86:238-242.

6. Iwase A, Suzuki Y, Araie M, et al. The Tajimi Study Group. The prevalence of primary open-angle glaucoma in Japanese. Ophthalmology. 2004;111:1641-1648.
7. Honjo M, Tanihara H, Inatani M, Honda Y. External trabeculotomy for the treatment of steroid-induced glaucoma. J Glaucoma. 2000;9: 483-485.

8. Mao AJ, Pan XJ, McIlraith I, Strasfeld M, Colev G, Hutnik C. Development of a prediction rule to estimate the probability of acceptable intraocular pressure reduction after selective laser trabeculoplasty in open-angle glaucoma and ocular hypertension. J Glaucoma. 2008; $17: 449-454$

9. Latina MA, Park C. Selective targeting of trabecular meshwork cells: In vitro studies of pulsed and $\mathrm{CW}$ laser interactions. Exp Eye Res. 1995;60:359-671.

10. Melamed S, Ben Simon GJ, Levkovitch-Verbin H. Selective laser trabeculoplasty as primary treatment for open-angle glaucoma: A prospective, nonrandomized pilot study. Arch Ophthalmol. 2003;121: 957-960.

11. Singh IP, Ahmad SI, Yeh D, et al. Early rapid rise in intraocular pressure after intravitreal triamcinolone acetonide injection. Am J Ophthalmol. 2004;138:286-287.

12. Levy J, Tessler Z, Klemperer I, Lifshitz T. Acute intractable glaucoma after a single low-dose sub-Tenon's corticosteroid injection for macular edema. Can J Ophthalmol. 2004;39:672-673.

13. Jonas JB, Degenring RF, Kamppeter BA, Kreissig I, Akkoyun I. Duration of the effect of intravitreal triamcinolone acetonide as treatment for diffuse diabetic macular edema. Am J Ophthalmol. 2004;138: $158-160$.
Clinical Ophthalmology

\section{Publish your work in this journal}

Clinical Ophthalmology is an international, peer-reviewed journal covering all subspecialties within ophthalmology. Key topics include: Optometry; Visual science; Pharmacology and drug therapy in eye diseases; Basic Sciences; Primary and Secondary eye care; Patient Safety and Quality of Care Improvements. This journal is indexed on Submit your manuscript here: http://www.dovepress.com/clinical-ophthalmology-journal

\section{Dovepress}

PubMed Central and CAS, and is the official journal of The Society of Clinical Ophthalmology (SCO). The manuscript management system is completely online and includes a very quick and fair peer-review system, which is all easy to use. Visit http://www.dovepress.com/ testimonials.php to read real quotes from published authors. 